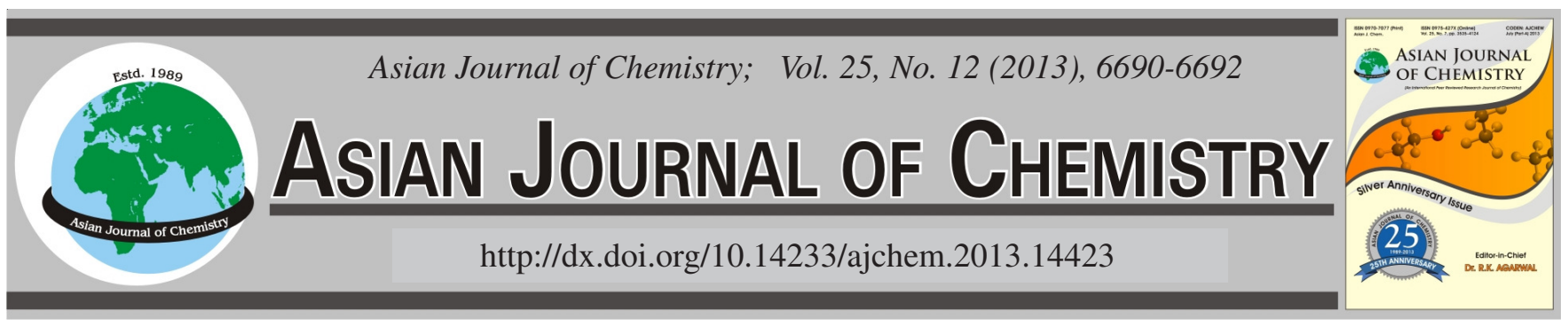

\title{
N-Arylation of Amines with o-Silylaryl Triflate
}

\author{
Y.G. LEE ${ }^{1}$, D.I. JUNG ${ }^{1, *}$ and J.T. HAHN ${ }^{2}$
}

${ }^{1}$ Department of Chemistry, Dong-A University, Busan 604714, Republic of Korea

${ }^{2}$ Department of Beautycare, Youngdong University, Youngdong 370701, Republic of Korea

*Corresponding author: Tel./Fax: +82 51 2007249; E-mail: dijung@ dau.ac.kr

(Received: 8 August 2012;

Accepted: 27 May 2013)

AJC-13550

An efficient, transition-metal-free procedure for the $\mathrm{N}$-arylation of amines $\mathbf{1}$ has been achieved by allowing those substrates to react with $o$-silylaryl triflate $\mathbf{2}$ in the presence of CsF. Good to excellent yields of arylated products $\mathbf{3}$ are obtained under very mild reaction conditions. This chemistry readily tolerates a variety of functional groups.

Key Words: N-Arylation, $o$-Silylaryl triflate, CsF, Amines.

\section{INTRODUCTION}

Establishing an efficient, reliable method for the Narylation of amines is currently active area of research in organic synthesis. Such aryl subunits are commonly found in a variety of biologically active and natural compounds ${ }^{1}$, agrochemicals $^{2}, \mathrm{HIV}-1$ protease inhibitors and compounds ${ }^{3}$ of interest in material science.

Traditionally ${ }^{4}$, the $\mathrm{N}$-arylation of amines has been carried out under copper-mediated Ull-mann-type conditions involving the coupling of amines with aryl halides ${ }^{5}$. Although these copper promoted reactions are useful, they usually require harsh reaction conditions and stoichiometric amounts of copper and the yields are not very reproducible ${ }^{6}$. Recently, a number of valuable new methods have been developed for the $\mathrm{N}$-arylation of amines ${ }^{7}$. Buchwald and Hartwig ${ }^{8,9}$ have demonstrated that the $\mathrm{Cu}$ - or $\mathrm{Pd}$-catalyzed $\mathrm{N}$-arylation of a variety of amines by aryl halides is a powerful method for the synthesis of arylamines. Despite these significant recent improvements, there still are limitations in present $\mathrm{N}$-arylation methods. For example, it is still difficult to present $\mathrm{N}$-arylation methodology may not accommodate certain organic functionality. Of the functional groups that are incompatible with the $\mathrm{Cu}$ - or $\mathrm{Pd}$ catalyzed $\mathrm{N}$-arylation methodology, the most important are probably halides. Most reaction conditions are fairly harsh, usually requiring high temperatures $\left(>110^{\circ} \mathrm{C}\right)$ and strong polar and often toxic solvents. The direct coupling of aromatic carboxylic acids and aryl halides or the carbonylation of aryl halides with a palladium catalyst to generate the corresponding aryl esters is difficult ${ }^{10}$. In the classical methods for esterification, a strong acid, such as sulfuric acid, is needed, which is not suitable for acid-sensitive compounds, can be corrosive and often produces side reactions, such as carbonization ${ }^{11}$. In this paper, we report an efficient an reliable procedure to $\mathrm{N}$ arylate amines under mild reaction conditions. Recently, silylaryl triflate $2^{12}$ has been employed to generate benzyne under mild reaction conditions, which can easily undergo a variety of synthetically useful nucleophilic ${ }^{13}$ and cycloaddition reactions ${ }^{14,15}$. However, the arylation of amines has not been widely studied due to the difficulty in generating arynes under convenient reaction conditions.

Recently, we reported reactions of 2-alkenyl- and 2hydrazinyl-1-methylpyrroles with aryne generated from silylaryl triflate under very mild reaction conditions provide excellent yields of arylated products, while tolerating many functional groups ${ }^{16}$. Here in, we wish to report the full details of this very efficient arylation procedure and our studies on the addition to silylaryl triflate.

\section{EXPERIMENTAL}

General procedure for the mono-N-arylation of aromatic amines. To a solution of $\mathrm{MeCN}(5 \mathrm{~mL})$, aromatic amine $(0.50$ $\mathrm{mmol})$ and silylaryl triflate $(0.50 \mathrm{mmol})$ was added $\mathrm{CsF}$ ( $1 \mathrm{mmol})$. The reaction mixture was allowed to stir at room temperature and monitored by TLC to establish completion of the reaction. The resulting solution was washed with brine $(20 \mathrm{~mL})$ and extracted with diethyl ether $(20 \mathrm{~mL})$. The combined ether fractions were dried over $\mathrm{Na}_{2} \mathrm{SO}_{4}$ and concentrated under reduced pressure. The residue was purified by flash chromatography on silica gel to afford the desired product. Diphenylamine (Table-1, entry 1). Purification by flash chromatography (30:1, hexane/EtOAc) afforded the indicated 
compound (38 mg) in a $92 \%$ yield as a white solid: m.p. 49$50{ }^{\circ} \mathrm{C}$ (lit. ${ }^{17} \mathrm{mp} \mathrm{50-52}{ }^{\circ} \mathrm{C}$ ). The ${ }^{1} \mathrm{H}$ and ${ }^{13} \mathrm{C}$ NMR spectra match the literature data ${ }^{18}$.

General procedure for the amines, 2,5-dimethoxytetrahydrofuran, 1,3-acetone carboxylic acid and silylaryl triflate. To a solution of $\mathrm{MeCN}(5 \mathrm{~mL})$, amines $(0.50 \mathrm{mmol})$, silylaryl triflate $(0.50 \mathrm{mmol}), 2,5$-dimethoxytetra hydrofuran $(0.50$ $\mathrm{mmol})$ and 1,3-acetone carboxylic acid $(0.50 \mathrm{mmol})$ was added CsF ( $1 \mathrm{mmol})$. The reaction mixture was allowed to stir at room temperature and monitored by TLC to establish completion of the reaction. The resulting solution was washed with brine $(20 \mathrm{~mL})$ and extracted with diethyl ether $(20 \mathrm{~mL})$.

The combined ethereal fractions were dried over $\mathrm{Na}_{2} \mathrm{SO}_{4}$ and concentrated under reduced pressure. The residue was purified by flash chromatography on silica gel to afford the desired product.

\section{RESULTS AND DISCUSSION}

Preparation of the aryne precursor: The aryne $\mathbf{2}$ were selected as substrate for our experiments. Aryne precursor $\mathbf{2}$ was selected as the simplest and most readily available aryne to study the scope of this chemistry. The synthesis of silylaryl triflate $\mathbf{2}$ has already been reported.

$\mathbf{N}$-Arylation of aromatic amines: Our initial studies focused on achieving optimal reaction conditions for the $\mathrm{N}$ arylated product using aniline and silylaryl triflate $\mathbf{1}$ as the model system. We first allowed 2-(trimethylsilyl)phenyl triflate 2 to react with 1 equiv of $\mathrm{CsF}$ and 1.2 equiv of aniline in $\mathrm{MeCN}$ at room temperature for $20 \mathrm{~h}$. Diphenylamine was obtained in an $90.2 \%$ yield and only a trace of triphenylamine was isolated. After trying several reactions, we found that THF was also a good solvent for the $\mathrm{N}$-arylation of aniline and $\mathrm{CsF}$ can be replaced by $n-\mathrm{Bu}_{4} \mathrm{NF}$ (TBAF). Although the reaction time can be dramatically decreased to $0.5 \mathrm{~h}$ when $\mathrm{nBu}_{4} \mathrm{NF}$ is allowed to react with the silylaryl triflate 2 to generate benzyne, the yield is a little lower. The optimal reaction conditions thus far developed employ $0.50 \mathrm{mmol}$ of aniline, 1.1 equiv of silylaryl triflate 2 and $0.15 \mathrm{~g}$ of $\mathrm{CsF}$ in $\mathrm{MeCN}(5 \mathrm{~mL})$ at room temperature for $24 \mathrm{~h}$. Diphenylamine was obtained in a 90.2 $\%$ yield (Scheme-I) (Table-1, entry 1$)$.

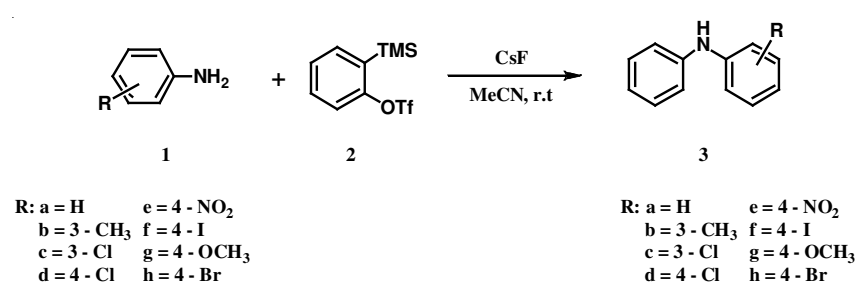

Scheme-I

We next studied the scope of this methodology by allowing a wide variety of aromatic amines to react with the silylaryltriflates $\mathbf{2}^{19}$. The results are summarized in Table-1. Aniline itself and aniline with electron-donating and withdrawing groups (Table-1, entries 1 and 3-8), such as nitro, iodo, bromo and methoxy groups, all react well with silylaryl triflate 2 and CsF to afford excellent yields of the desired phenyl-substituted products. It is noteworthy that haloanilines also react with silylaryl triflate $\mathbf{2}$ to generate the desired halosubstituted products in excellent yields (Table-1). Halides, which are unlikely to survive under the Pd-mediated amination reaction conditions are readily accommodated by our reaction conditions. In order to synthesize biologically active com-pounds, when the reaction of amines (aniline, $m$-toluidine, 3 chloroaniline, 4-chloroaniline), 2,5-dimethoxytetra-hydrofuran, 1,3-acetone dicarboxylic acid and silylaryl triflate $\mathbf{2}$ (Tables 2 and 3), good yields of the $\mathrm{N}$-arylated products are still obtained (Schemes II and III).

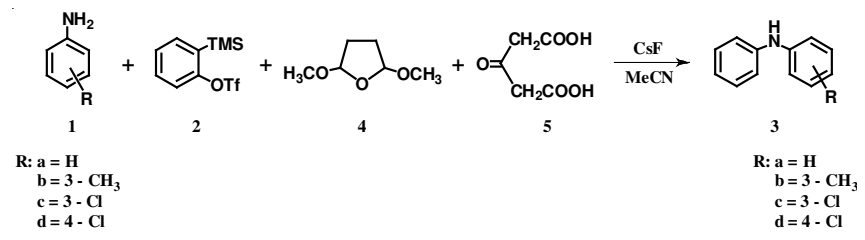

Scheme-II

TABLE-1

FACILE N-ARYLATION OF AROMATIC AMINES

\begin{tabular}{|c|c|c|c|c|c|c|}
\hline Entry & Amine 1 & Silylaryltriflate $(\mathrm{mmol}) 2$ & $\mathrm{CsF}(\mathrm{mmol})$ & Time (h) & Product 3 & Isolated yield (\%) \\
\hline 1 & a & 0.5 & 1 & 24 & & 90.2 \\
\hline 2 & $\mathrm{~b}$ & 0.5 & 1 & 24 & & 92.1 \\
\hline 3 & $\mathrm{c}$ & 0.5 & 1 & 24 & & 84.3 \\
\hline 4 & $d$ & 0.5 & 1 & 24 & & 86.6 \\
\hline 5 & $\mathrm{e}$ & 0.5 & 1 & 24 & & 85.7 \\
\hline 6 & $\mathrm{f}$ & 0.5 & 1 & 24 & & 92.2 \\
\hline 7 & $\mathrm{~g}$ & 0.5 & 1 & 24 & & 89.5 \\
\hline 8 & $\mathrm{~h}$ & 0.5 & 1 & 24 & & 91.1 \\
\hline
\end{tabular}

${ }^{a}$ All reactions were run under the following reaction conditions, under otherwise specified: $0.50 \mathrm{mmol}$ of amine and the indicated amount of silyaryl triflate and $\mathrm{CsF}$ were stirred in $5 \mathrm{~mL}$ of $\mathrm{MeCN}$ at room temperature. Only monoarylated product was obtained. 


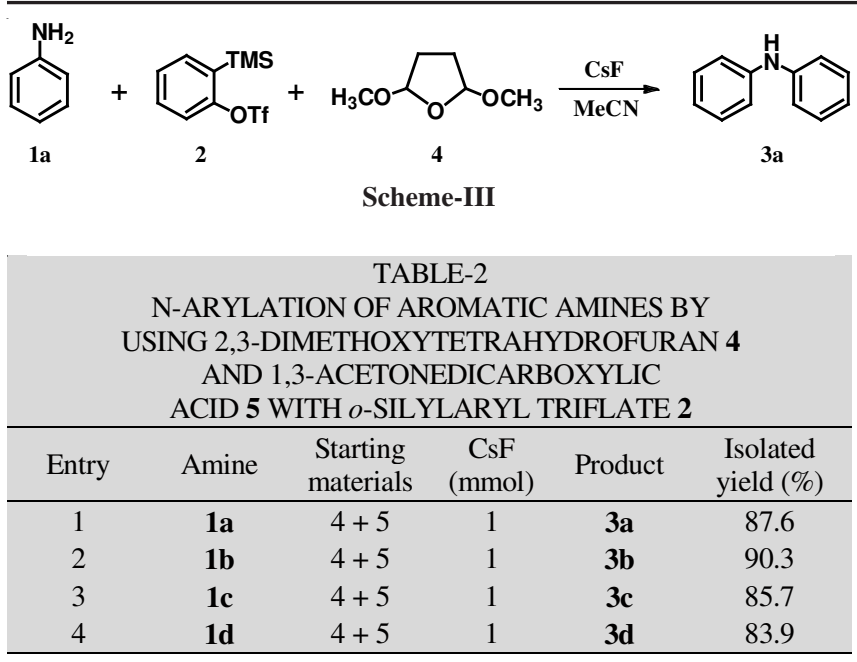

\begin{tabular}{cccccc}
\multicolumn{7}{c}{ TABLE-3 } \\
N-ARYLATION OF AROMATIC AMINES \\
BY USING 2,5-DIMETHOXYTETRAHYDROFURAN \\
WITH 0 -SILYLARYL TRIFLATE 2 \\
\hline Entry & Amine & $\begin{array}{c}\text { Starting } \\
\text { materials }\end{array}$ & $\begin{array}{c}\text { CsF } \\
(\mathrm{mmol})\end{array}$ & Product & $\begin{array}{c}\text { Isolated } \\
\text { yield }(\%)\end{array}$ \\
\hline 1 & 1a & 4 & 1 & 3a & 89.8 \\
\hline
\end{tabular}

Substantially we reported ${ }^{20,21}$ the synthesis of N-substituted pyrroles and nortropinones in the reaction of amines with 2,5dimethoxytetrahydrofuran and 1,3-acetone dicarboxylic acid. When the reaction of aniline, 2,5-dimethoxytetrahydrofuran and silylaryltriflate 2 with $\mathrm{CsF}$ in $\mathrm{MeCN}$ executed, good yield of diphenylamine as a $\mathrm{N}$-arylated product is still obtained. But synthesis of $\mathrm{N}$-substituted pyrrole and nortropinone did not occur (Tables 2 and 3).

In summary, from Table-1, one can see that almost all aromatic amines react well with silylaryl triflate and $\mathrm{CsF}$ under very mild reaction conditions to afford good to excellent yields of the desired products. It should be pointed out that a variety of other functional groups, including halide should be readily tolerated under present reaction conditions.

\section{Conclusion}

An efficient, mild, transition-metal-free method is developed for the $\mathrm{N}$-arylation of amines. Monoarylated amines can easily be obtained from primary amines by simply controlling the ratio of the reactants. A variety of functional groups are compatible with the reaction conditions, including nitro, iodo, bromo and methoxy groups. It is also shown that halides, which are not compatible with Pd-mediated arylation procedures, readily tolerate the reaction conditions.

\section{ACKNOWLEDGEMENTS}

This work was supported by the grant from Dong-A University (2012).

\section{REFERENCES}

1. (a) M. Negwer, In Organic-Chemical Drugs and their Synonyms (An International Survey), Akademie Verlag GmbH: Berlin, Germany, edn. 7 (1994); (b) A.W. Czarnik, Acc. Chem. Res., 29, 112 (1996); (c) Y.
Hong, C.H. Senanayake, T. Xiang, C.P. Vandenbossche, G.J. Tanoury, R.P. Bakale and S.A. Wald, Tetrahedron Lett., 39, 3121 (1998); (d) D.L. Romero, R.A. Morge, M.J. Genin, C. Biles, M. Busso, L. Resnick, I.W. Althaus, F. Reusser, R.C. Thomas and W.G. Tarpley, J. Med. Chem., 36, 1505 (1993); (e) D.A. Evans, K.M. DeVries, In ed.: R. Nagarajan, In Glycopeptide Antibiotics, Drugs and the Pharmaceutical Sciences; Marcel Decker, Inc.: New York, Vol. 63, pp. 63-104 (1994); (f) K.C. Nicolaou and N.C.B. Christopher, J. Am. Chem. Soc., 124, 10451 (2002).

2. G.W.A. Milne, CRC Handbook of Pesticides, CRC Press: Boca Raton, FL (1994).

3. S.R. Turner, J.W. Strohbach, R.A. Tommasi, P.A. Aristoff, P.D. Johnson, H.I. Skulnick, L.A. Dolak, E.P. Seest, P.K. Tomich, M.J. Bohanon, M.M. Horng, J.C. Lynn, K.-T. Chong, R.R. Hinshaw, K.D. Watenpaugh, M.N. Janakiraman and S. Thaisrivongs, J. Med. Chem., 41, 3467 (1998).

4. (a) F.E. Goodson and J.F. Hartwig, Macromolecules, 31, 1700 (1998); (b) F.E. Goodson, S.I. Hauck and J.F. Hartwig, J. Am. Chem. Soc., 121, 7527 (1999); (c) R.A. Singer, J.P. Sadighi and S.L. Buchwald, J. Am. Chem. Soc., 120, 213 (1998).

5. (a) F. Ullmann, Ber. Dtsch. Chem. Ges., 36, 2382 (1903); (b) H.B. Goodbrand and N.-X. Hu, J. Org. Chem., 64, 670 (1999); (c) F. Ullmann, Chem. Ber., 37, 853 (1904).

6. (a) J. Lindley, Tetrahedron, 40, 1433 (1984); (b) J. Hassan, M. Sevignon, C. Gozzi, E. Schulz and M. Lemaire, Chem. Rev., 102, 1359 (2002).

7. (a) F.Y. Kwong and S.L. Buchwald, Org. Lett., 5, 793 (2003); (b) F.Y. Kwong, A. Klapars and S.L. Buchwald, Org. Lett., 5, 581 (2003); (c) H. He and Y.-J. Wu, Tetrahedron Lett., 44, 3385 (2003); For a Recent review See: (d) J.S. Sawyer, Tetrahedron, 56, 5045 (2000); (e) F. Theil, Angew. Chem., Int. Ed., 38, 2345 (1999).

8. (a) J.P. Wolfe, J.-F. Marcoux and S.L. Buchwald, Acc. Chem. Res., 31, 805 (1998); (b) D. Zim and S.L. Buchwald, Org. Lett., 5, 2413 (2003); (c) M.C. Harris, X. Huang and S.L. Buchwald, Org. Lett., 4, 2885 (2002); (d) J.P. Wolfe, H. Tomori, J.P. Sadighi, J. Yin and S.L. Buchwald, J. Org. Chem., 65, 1158 (2000); (e) A. Aranyos, D.W. Old, A. Kiyomori, J.P. Wolfe, J.P. Sadighi and S.L. Buchwald, J. Am. Chem. Soc., 121, 4369 (1999); (f) J. Marcoux, S. Doye and S.L. Buchwald, J. Am. Chem. Soc., 119, 10539 (1997); (g) S.-I. Kuwabe, K.E. Torraca and S.L. Buchwald, J. Am. Chem. Soc., 123, 12202 (2001).

9. (a) J.F. Hartwig, Acc. Chem. Res., 31, 853 (1998); (b) J.F. Hartwig, Angew. Chem., Int. Ed., 37, 2046 (1998); (c) G. Mann, C. Incarvito, A.L. Rheingold and J.F. Hartwig, J. Am. Chem. Soc., 121, 3224 (1999).

10. (a) T. Yamamoto, Synth. Commun., 9, 219 (1979); (b) C. Ramesh, Y. Kubota, M. Miwa and Y. Sugi, Synthesis, 2171 (2002).

11. (a) E. Fischer, Ber., 28, 3254 (1895); (b) J. Butts, J. Am. Chem. Soc., 53, 3560 (1931).

12. Y. Himeshima, T. Sonoda and H. Kobayashi, Chem. Lett., 1211 (1983).

13. (a) H. Yoshida, H. Fukushima, J. Ohshita and A. Kunai, Angew. Chem., Int. Ed., 43, 3935 (2004); (b) H. Yoshida, S. Sugiura and A. Kunai, Org. Lett., 4, 2767 (2002).

14. H. Yoshida, M. Watanabe, H. Fukushima, J. Ohshita and A. Kunai, Org. Lett., 6, 4049 (2004).

15. M. Beller, C. Breindl, T.H. Riermeier and A. Tillack, J. Org. Chem., 66, 1403 (2001).

16. (a) Z. Liu and R.C. Larock, Org. Lett., 5, 4673 (2003); (b) Z. Liu and R.C. Larock, Org. Lett., 6, 99 (2004).

17. C. Desmarets, R. Schneider and Y. Fond, J. Org. Chem., 67, 3029 (2002).

18. N. Kataoka, Q. Shelby, J.P. Stambuli and J.F. Hartwig, J. Org. Chem., 67, 5553 (2002).

19. 4-Aminopyridine and 2-Aminopyridine React with the Silylaryl Triflate 1a to Afford an Unknown Salt; No N-Arylated Products were Isolated under our Usual Reaction Conditions.

20. D.I. Jung, J.H. Song, Y.H. Kim, D.H. Lee, H.A. Song, Y.G. Lee, Y.M. Park, S.K. Choi, J.T. Hahn and S.J. Cho, Bull. Korean Chem. Soc., 25, 1932 (2004).

21. D.I. Jung, J.H. Song, D.H. Lee, Y.H. Kim, Y.G. Lee and J.T. Hahn, Bull. Korean Chem. Soc., 27, 1493 (2006). 